\title{
EDUCAÇÃO AMBIENTAL, \\ DEMOCRACIA E PEDAGOGIA \\ FREIREANA: UMA POSSÍVEL \\ ARTICULAÇÃO NO CONTEXTO DA \\ ILHA DE BUBAQUE (GUINÉ-BISSAU)
}

Loriana Guimarães Borges do Canto Moreira ${ }^{1}$

Resumo: A llha de Bubaque, assim como as demais ilhas pertencentes ao Arquipélago das Bijagós (Guiné-Bissau), contempla cotidianamente o isolamento, o esquecimento e a exposição clamorosa de suas vulnerabilidades enquanto anela por voz, dignidade e justiça social. O presente artigo parte de uma pesquisa de mestrado em andamento e objetiva, através dos dados expostos a seguir, anunciar a efetiva similitude conexa presente nos conceitos democráticos e político-pedagógicos freireanos e nos conceitos que permeiam a Educação Ambiental num enfoque emancipatório, como potenciais articuladores de reumanização da comunidade insular de Bubaque a partir de sua implementação conjunta.

Palavras-chave: Guiné-Bissau; Educação Ambiental; Democracia; Pedagogia Freireana.

Abstract: The Bubaque Island, as well as the other islands belonging to the Bijagós Archipelago (Guinea-Bissau), daily contemplates the isolation, the oblivion and the clamorous exposure of its vulnerabilities while it yearns for a voice, dignity and social justice. This article is part of a master's research and aims, through the data presented below, to announce the effective similarity present in Freirean democratic and political-pedagogical concepts and concepts that permeate the Environmental Education in an emancipatory approach, as potential articulators of rehumanization of the island community of Bubaque from its joint implementation.

Keywords: Guinea-Bissau; Environmental Education; Democracy; Freirean Pedagogy.

1 Universidade Federal do Paraná. E-mail: Iorianamoreira@gmail.com Link para o Lattes: http://lattes.cnpq.br/8413962294324308

Revbea, São Paulo, V.16, № 5: 270-287, 2021. 


\section{Introdução}

Este texto aborda a Educação Ambiental como educação emancipatória que compreende ações integradas nos âmbitos ambiental, social, econômico, histórico e cultural, construindo valores capazes de reumanizar as pessoas a partir de sua multiplicidade e objetivos que se vigoram em concordância com a política educacional libertadora criada e defendida por Paulo Freire.

As similaridades encontradas entre as propostas libertadoras da Educação Ambiental apresentadas e debatidas a partir de uma perspectiva crítica e do legado de Paulo Freire, revelaram-se complementares conceitual, prática e objetivamente. Para a dialogação da Educação Ambiental nesta perspectiva crítica, os autores escolhidos foram selecionados mediante revisão bibliográfica por conveniência.

As obras de Paulo Freire têm fundamentação na "reflexão sobre a ação educativa transformadora dos homens e do mundo, contra a opressão e a injustiça social, tendo como horizonte a construção de uma nova sociedade" (PERNAMBUCO; SILVA, 2006, p. 208). Carvalho (2004), ao discorrer quanto às raízes da Educação Ambiental numa perspectiva crítica, observa que esta tem seus fundamentos nos ideais democráticos e emancipatórios do pensamento crítico aplicado à educação, da qual, Paulo Freire é referência fundadora na defesa da educação como formação de sujeitos sociais emancipados.

Nesta perspectiva, Educação Ambiental faz-se educação imersa na vida, na história e nas questões urgentes de nosso tempo, que acrescenta especificidade de compreensão das relações sociedade-natureza, intervenção sobre problemas e conflitos ambientais e inserção de modelo para a formação de indivíduos e grupos sociais capazes de identificar, problematizar e agir em relação às questões socioambientais (CARVALHO, 2004).

Emerge assim, a inquietação pungente que origina o presente artigo: $D e$ que maneira pode-se promover transformação socioambiental em Bubaque (Guiné-Bissau) através do ensino a partir da associação entre Educação Ambiental $e$ as práticas político-pedagógicas freireanas, tendo como pressupostos o sentimento de responsabilidade e pertencimento, preservação dos recursos naturais e autonomia socioeconômica da comunidade? Todavia, este artigo não tem por pretensão responder ao conjunto de problemáticas subjetivadas em seu cerne e, tampouco o poderia. Antes, visa, a partir da explanação a respeito do contexto de vulnerabilidade, instabilidade sociopolítica e socioambiental de Guiné-Bissau e das ilhas habitadas do Arquipélago das Bijagós, promover a reflexão quanto ao potencial emancipatório resultante da associação entre a implementação da Educação Ambiental numa perspectiva crítica, das práticas pedagógicas freireanas e das concepções de Freire quanto a democracia, como processos complementares articuladores da reumanização do indivíduo, em especial, no contexto insular de Bubaque. 
Para tanto, num primeiro momento, o artigo discorre a respeito do contexto histórico, político e social de Guiné-Bissau, seu árduo processo de liberdade, impactos e reflexos sobre suas comunidades, com enfoque nas vulnerabilidades da llha de Bubaque. Em um segundo momento, traz um diálogo quanto aos conceitos apresentados como possíveis articuladores emancipatórios neste contexto e em seguida, propõe uma reflexão quanto as concepções de democracia segundo Freire, assim como suas concepções político-pedagógicos e a perspectiva de Educação Ambiental num enfoque emancipatório.

\section{Trajetória Guineense: da busca por liberdade aos impactos sobre o ambiente e as comunidades insulares}

A busca por democracia, o esforço em tornar-se uma república e a luta que esta busca representa, encontram-se no cerne da trajetória de GuinéBissau, assim como das ilhas que compõem o Arquipélago das Bijagós. A llha de Bubaque, parte deste arquipélago, torna-se o lócus escolhido para análise e reflexão da presente pesquisa.

Para melhor compreensão da relação existente entre a luta por democracia guineense e sua relação com a implementação de uma política ambiental no país, faz-se necessário compreender o contexto em que ambas ocorrem na República de Guiné-Bissau. Segundo o recenseamento realizado pelo Instituto Nacional de Estatística e Censo (INEC) de 2009 (SUCUMA apud. INEC, 2017, p. 130), Guiné-Bissau é uma República com $36.125 \mathrm{~km}^{2}$, situada no continente africano, concretamente na costa ocidental da África, banhada pelo oceano Atlântico. Faz fronteira ao norte com República do Senegal e ao sul com a República da Guiné Konakry, com uma população de 1.548.159 habitantes.

Assim como o Brasil, Guiné-Bissau foi colônia de Portugal. Por mais de trezentos anos esteve sujeita a Portugal como colônia até a declaração de sua independência em 1973. Liberdade alcançada mediante luta armada deste povo que preferiu as armas à permanência da condição de colônia de exploração a qual, contrariamente, encontrava-se.

Portugal reconheceu a independência de Guiné-Bissau apenas no ano de 1974, tornando-Ihe a primeira colônia portuguesa da África a separar-se oficialmente de Portugal. Guiné-Bissau protagonizava assim, sua vocalização por liberdade e transformação e, neste contexto de guerrilha e pósindependência, Paulo Freire escreve as cartas que compõem seu livro Cartas a Guiné-Bissau (1978).

No referido livro, Freire relata as visitas realizadas ao país a convite do Comissariado de Educação a fim de discutir as bases da colaboração solicitada no campo da alfabetização de adultos: 
Para que a alfabetização pudesse cumprir o seu principal objetivo - o de inserida no esforço de reconstrução nacional, contribuir, efetivamente, para este esforço - era necessário que se encontrasse em dinâmica relação com outras formas básicas de intervenção social, capazes de inscrevê-la como uma necessidade (FREIRE, 1978, p. 28).

Diante do contexto pós-guerrilha apresentado, no esforço de reconstrução da nação e na formulação das próprias legislações, suscitam as fragilidades e as vulnerabilidades emergentes, em especial, no que tange a instabilidade política instaurada nos anos subsequentes à conquista de independência. Instabilidade política agravada pela morte de Amílcar Cabral e por golpes de estado militares ocorridos nos anos conseguintes, os quais transpareceram os interesses recônditos de líderes que, voltando ao modelo de sociedade fechada, autoritária e colonial, usaram do poder para mais uma vez tentar emudecer seu povo, explorá-lo, resultando lamentavelmente, no insucesso de implementação de um estado de direito democrático.

A perpetuação da ausência de liberdades substantivas (SEN, 2000) pósindependência, manifestam a ininterrupção colonial exposta por Ballestrin (2013): a colonialidade do poder, do saber e do ser. Colonialidade subjetiva de tripla dimensão que perpetua a relação de poder mediante o controle sobre os fatores basilares essenciais à real liberdade: economia, política, autoridade, Natureza, conhecimento... (BALLESTRIN, 2013; SEN, 2000).

Horkheimer (1976) afirma que

por detrás da pura lei econômica, da lei do mercado e do lucro, encontra-se a pura lei do poder de uma minoria, baseada na posse dos instrumentos materiais de produção, de forma que a tendência ao lucro acaba sendo o que sempre foi, ou seja, a tendência ao poder social (apud. FARIA, 2018, p. 7, grifo da autora).

Na década de oitenta, segundo Cruz (2000), o Direito do Ambiente Guineense foi estabelecido percebendo-se alguma preocupação com temáticas ambientalistas nomeadamente nas políticas sociais relativas à água e saneamento, e nas questões concernentes à desertificação. Antes deste período, poucas contribuições legais voltadas ao ambiente foram implementadas, especificamente, nas décadas de cinquenta e sessenta. Outrossim, os anos oitenta representaram o início das mudanças nas políticas econômicas, porém, as questões ambientais não haviam ainda recebido a notoriedade necessária face aos centros de decisão, para figurar nas políticas públicas do Governo, das poucas expressões de preocupações percebidas.

Cruz (2000) destaca que o Direito do Ambiente resulta de um conjunto de regras, normas e princípios dispersos por uma diversidade de leis, não se 
tratando de um direito sistematicamente construído. Leis as quais, nas palavras do autor, seriam chamadas de "parcial e incidentalmente ambientais, na medida em que concebidas com outros tipos de preocupações" (CRUZ, 2000, p. 127). Logo, fixa-se este conjunto de leis voltado ao regime econômico com prioridade de exploração dos recursos naturais ou com relevante impacto sobre os recursos naturais como, por exemplo, a legislação referente à exploração de pedreiras, florestas e pesca, entre outras (CRUZ, 2000).

Como expõem Panzo (2017), em 2011 o país promulgou a Lei de Base do Ambiente $\mathrm{n}^{\circ}$ 1/2011 a qual, apesar de ser a primeira lei a apresentar significativo compromisso com a preservação do meio ambiente guineense, infelizmente, ainda se mostra ineficiente. Ainda que considerando os recursos naturais nacionais como propriedade do Estado, Silva (2018) destaca a abertura encontrada na constituição guineense que proporciona acesso a estes recursos a particulares mediante concessões administrativas ou acordos periódicos.

A inacessibilidade democrática sobre o processo de feitura das leis, bem como a ausência de um processo de democratização das instituições do Estado e da sociedade civil, em particular no que tange o movimento civil ambientalista (CRUZ, 2000), se tornam dificultadores da efetividade protetiva destas leis. O autor ressalta ainda, que os valores ambientais adotados pela sociedade em cada tempo, conformam o Direito do Ambiente do tempo em questão e que serão estes valores eleitos em razão de uma identificação e formulação de problemas ambientais, resultando desta última, a definição das soluções e dos tipos de leis a adotar para resolvê-los.

Nos anos 1990, com o movimento de renovação da legislação, quer pela revisão de leis existentes, quer pela feitura de novas leis, nomeadamente estas promovem a implementação de algumas leis ambientais que visam a preservação ambiental e o uso sustentável dos recursos naturais, assistidas pela cooperação internacional. Porém, no que tange à sistemática, o estado de dispersão das disposições sobre o ambiente revelou fraquezas do quadro jurídico ambiental, despontando aspectos relacionados à falta de transparência, previsibilidade, gerenciamento, administração e baixa eficácia dessas mesmas disposições por falta de mecanismos de verificação, tanto de implementação quanto de aferição de aplicação (CRUZ, 2000).

Problemas ainda percebidos nos dias atuais, avultados na vivência cotidiana de uma nação em constante tentativa de reconstrução e mediante as precariedades que permeiam a vida de considerável parcela da população de Guiné-Bissau, especialmente as que compõem as comunidades insulares pertencentes as áreas habitadas do Arquipélago das Bijagós.

Segundo Madeira (2016), no que diz respeito à gestão do espaço e proteção ambiental, o Arquipélago apresentou melhorias. Em 1996 o arquipélago foi intitulado Reserva da Biosfera pela UNESCO e parques nacionais foram criados pelo Estado da Guiné-Bissau em dois grupos de ilhas: o Grupo do Sul em Orango (Orango National Parque - PNO), Centro de Hipopótamos de Água Salgada, e Grupo Oriental em João Vieira Poilão (Parque Nacional João Vieira 
Polão - PNMJVP), Centro das Tartarugas Marinhas. Além destes, a Área de Proteção Comunitária nas ilhas de Formosa, Nago e Chediã (Urok) também foram criadas com o intuito de preservação da diversidade biológica local, todavia, apesar de aparentemente promissor quanto aos avanços ambientais acenando para a emancipação e sustentabilidade da população insular guineense, muitas são as vulnerabilidades expostas, ainda ignoradas.

Polet, Barros e Ramos (2011) expõem a exploração ligada ao mercado turístico, destacando a oferta de subempregos de caráter correntemente sazonal, com remunerações insuficientes para subsistência. Os autores denunciam a corroboração do mercado turístico com o prosseguimento dos processos de risco social, dentre os quais os autores destacam a migração, a perda territorial, o deslocamento compulsivo de populações locais, a perda cultural, a dependência alimentar do exterior, a exploração de mão de obra infantil e a exploração sexual. Comunidades inteiras esquecidas enquanto povos de direitos, não obtendo acesso ao básico à sua subsistência, mas lembrado quanto às riquezas naturais com desejável potencial exploratório, permitindoIhes desumanamente, um padrão mínimo de sobrevivência.

Ainda, dos muitos problemas enfrentados com regularidade pelos habitantes do Arquipélago, Madeira (2016) destaca a própria insularidade ${ }^{2}$, a ausência de saneamento básico, as dificuldades quanto ao transporte e a comunicação entre ilhas, transporte e comunicação com o continente, inacessibilidade de assistência médica, analfabetismo, fluxo de migrantes, alta taxa de mortalidade, produção insuficiente de alimentos, vulnerabilidade dos ecossistemas, fragilidade de gestão, carência de profissionais especializados, falta de investimento de recursos, entre outros.

O sentimento de isolamento unido à escassez em que as comunidades se encontram, em cuidados de saúde, educação, transporte e comunicação são, ainda, uma barreira séria para um desenvolvimento populacional. Coeficientes que evidenciam os efeitos da relação de poder e domínio moderna, fruto da incessante busca por acúmulo de capital característica do absolutismo econômico concernente à perspectiva de desenvolvimento econômico neoliberal.

Tanto mais pobre seja uma nação, e mais baixos os padrões de vida das classes inferiores, maior será a pressão dos estratos superiores sobre elas, [...] consequentemente, os mais altos estratos tendem a encarar os direitos políticos dos mais baixos, particularmente o de interferir no poder, como coisa absurda e imoral (FREIRE, 1999, p. 86).

\footnotetext{
${ }^{2}$ Insularidade: Qualidade do que é insular; conjunto dos fenômenos geográficos característicos das ilhas, notadamente a falta de comunicação por terra; situação de um país que forma uma ilha ou um arquipélago. INSULARIDADE. in: PRIBERAM, Dicionário da Língua Portuguesa, Priberam Informatica S.A, 2021.

Disponível em: <https://dicionario.priberam.org/insularidade>. Acesso em: 21/03/2021.
} 
Em suma, as condições de precariedade sofridas pela população local explicitam a conduta exploratória de um regime político regido por representantes populares que, inicialmente, lutaram empaticamente pelos mesmos direitos que hoje negam à população. Empatia esta, esquecida a cada avanço alçado à estratos sociais superiores, tornando os governantes levianamente indiferentes às causas basilares de um Estado de direito democrático, suprimindo, tolhendo e emudecendo seu povo.

\section{Diálogo Reflexivo: Pedagogia Freireana, Educação Ambiental e Democracia}

"Onde buscarmos as condições de que tivesse emergido uma consciência popular democrática, permeável e crítica, sobre a qual se tivesse podido fundar autenticamente o mecanismo do estado democrático, messianicamente transplantado?", pergunta Freire ao leitor (1999, p. 88). Ao ler esse questionamento, somos incapazes de identificar prontamente a qual país o autor se refere, Brasil ou Guiné-Bissau; cada qual com suas individualidades, singularidades, porém unidos, irmãos, frente às proximidades, familiaridades e heranças históricas e culturais de ambos os países lusófonos.

Ao analisarmos o ano em que ocorreu a publicação do texto citado, nos deparamos mais uma vez com a contemporaneidade característica das obras de Freire. Contemporaneidade esta, que nos remete à reflexão a respeito da democracia que ainda buscamos e o pouco avanço que fizemos desde então.

Freire (1999, p. 99) elucida que

a democracia que, antes de ser forma política, é forma de vida, se caracteriza sobretudo por forte dose de transitividade de consciência no comportamento do homem. Transitividade que não nasce e nem se desenvolve a não ser dentro de certas condições em que o homem seja lançado ao debate, ao exame de seus problemas e dos problemas comuns. Em que o homem participe [...] uma ação democrática em geral, tem que ser feita não só com o consentimento do povo, mas com suas próprias mãos.

A transitividade é alcançada por uma postura dialógica fundamentada no respeito à participação efetiva de uma população na construção coletiva de seu país.

Assim como Freire (1999), Chauí (2012) apresenta concepções de democracia que dão completude ao conceito, muito além de uma classificação de regime político. Dentre elas, destaca-se o conceito ao qual Chauí caracteriza como 
forma sociopolítica que busca enfrentar as dificuldades [...] conciliando os princípios da igualdade e da liberdade e a existência real das desigualdades, bem como o princípio da legitimidade do conflito e a existência de contradições materiais que introduzem, para isso, a ideia dos direitos (econômicos, sociais, políticos e culturais) (CHAUÍ, 2012, p. 53-54).

Logo, uma sociedade é democrática quando institui direitos mediante a abertura do campo social à criação de direitos reais, à ampliação de direitos existentes e à criação de novos direitos, enfatizando que a democracia é a sociedade verdadeiramente histórica, aberta ao tempo, às transformações e ao novo (CHAUí, 2012). Desta forma, a democracia configura-se na vocalização de um povo como forma de tradução de seus anseios, suas ações, seus esforços, sua batalha contra o mutismo que insistentemente o tenta calar, da expressão real e genuína de um povo por alcançar libertação e construir sua emancipação. Anseio por transformação. Esperança democrática como forma política, como forma de vida e como direito de uma sociedade de um Estado de direito democrático.

Enquanto direito deste povo brasileiro ou guineense, a democracia lamentavelmente persiste como prática aparente cotidiana, ilusória, expondo-se insuficiente, desmascarada pela manipulação e falta de diálogo, tanto daqueles que a ignoram quanto daqueles que se valem de seus conceitos, valores e objetivos para nunca a promover, dando continuidade à manipulação a qual não se pretende abandonar, através de uma falsa implementação e vivência democrática.

Neste contexto, a ânsia por transformações mais concretas e menos ilusórias, perpetua-se. Transformações emergentes que perpassam por todos os âmbitos sociais (socioeconômico, socioambiental, político-ambiental, políticoeconômico, entre outros). Todos, âmbitos tocados e carentes desta democracia genuína aclarada por Freire e Chauí e, inevitavelmente, todos perpassando o âmbito ambiental; intrinsecamente ligados a ele, dependentes dele e com expectativas cada vez mais egoístas sobre ele.

O Desenvolvimento Sustentável, inicialmente, propôs-se a tornar-se o espaço de convergência entre interesses econômicos, desenvolvimento e preservação de recursos naturais. Deveria ser o modelo o qual "atende às necessidades do presente sem comprometer a possibilidade de as gerações futuras atenderem as suas próprias necessidades" (BRUNDTLAND, 1988, p. 46).

Democracia, equidade, respeito aos diferentes povos e suas culturas, erradicação da pobreza, justiça social, manejo adequado de recursos naturais e proteção ambiental, compreendem alguns dos aspectos fundamentais basilares da Agenda 21 (FARIA, 2018). Porém, conforme afere este mesmo documento, a disformidade da proposição inicial do Desenvolvimento Sustentável de modelo econômico equilibrado política, social, cultural e ambientalmente, para modelo 
ecologicamente predatório, socialmente perverso, politicamente injusto, culturalmente alienado e eticamente repulsivo (FARIA, 2018; TEIXEIRA, 2008; JACOBI, 2005), se materializa.

Os processos necessários à práxis da Sustentabilidade manifestam-se no coletivo, nas relações sociais, na contemplação e integração entre e para todos, ou seja, num verdadeiro estado de direito democrático. A sustentabilidade e os mecanismos inerentes à sua práxis, perpassam o indivíduo interlocutor deflagrando-se efetivamente nas dinâmicas públicas e sociais, sendo inconcebíveis posturas individualistas que privilegiam uma minoria em detrimento de seus semelhantes, bem como, a responsabilização do sujeito social como promotor unilateral de transformações sociais, ou tampouco, manifestações com aparente viés ecológico que no exercício das ações, exprime primordial engajamento com a promoção do desenvolvimento econômico e o acúmulo de capital.

A Educação Ambiental propõe a reflexão, o debate e o enfrentamento multidisciplinar destes e outros dilemas. Em perspectiva crítica, se propõe a desvelar a realidade e instrumentalizar os atores sociais partícipes dessa realidade para que, a partir da práxis, a reflexão subsidie uma prática criativa e a prática reverbere em construção de uma nova compreensão de mundo (GUIMARÃES, 2004). Propondo-se esfera convergente entre as diferentes racionalidades que envolvem as dinâmicas sociais para construção de um avanço reflexivo, dialógico e prático, para um novo viver e fazer socioambiental.

Caride e Meira (2001) apresentam aspectos paradoxais sobre a Educação Ambiental e as crises relacionadas ao desenvolvimento humano, no que tange 0 desenvolvimento econômico das chamadas "sociedades avançadas". Na tentativa de responder satisfatoriamente às tensões econômicas emergentes das últimas décadas, a educação entra como uma das estratégias adotadas, sendo usada como ferramenta para o desenvolvimento destas sociedades, no cumprimento de tarefas que "procuram enfatizar a contribuição para o bem-estar individual e coletivo, incluindo a modificação estrutural e/ou funcional dos ambientes naturais ou construídos" (CARIDE; MEIRA, 2001, p. 9, tradução da autora).

Estes mecanismos estratégicos, segundo os autores, deslocam a educação para estratos superiores, acima de questões como a igualdade de oportunidades sociais, a democratização, a preservação do meio ambiente e a formação em valores, culminando em resultados sociais desiguais e controversos. Uma vez que a Educação se sujeita condescendentemente a ser participante de mecanismos como estes, perde sua essencialidade emancipatória, crítica e democrática, se permitindo transfigurar retrogradamente em "fábrica" produtora de indivíduos e grupos sociais formatados para preconização do desenvolvimento econômico ao invés do desenvolvimento humano. Uma formatação social tecnicista propiciada por um discurso pedagógico, político e social justificáveis do ponto de vista destas chamadas 
"sociedades avançadas", porém, totalmente contraditória, controversa aos fundamentos essenciais defendidos por Freire (1999).

$\mathrm{Na}$ medida em que a consciência social permanece restrita quanto às implicações e impactos destrutivos do modelo de desenvolvimento em curso, os obstáculos à dialogação se agigantam (JACOBI, 2005). Não obstante, reconhecidamente a educação compreende em processo de reflexão crítica que conduz o sujeito à apreensão de consciência do seu mundo vivido, numa atitude crítico-prática transformadora de sua realidade (FREISLEBEN, 2013) se configurando em uma área de vital importância para o desenvolvimento humano.

A educação pode ser compreendida enquanto práxis sociais, como o "aprimoramento humano naquilo que pode ser aprendido e recriado a partir dos diferentes saberes existentes em uma cultura, de acordo com as necessidades, possibilidades e exigências de uma sociedade", conforme reflete Loureiro (2006, p. 136). No entanto, a educação formal não se basta, tanto dentro quanto fora dos muros. Para que a educação se faça promotora de racionalidade que norteie o desenvolvimento de criticidade para promoção e ampliação dialógica, os processos educacionais precisam irromper com a tradicionalidade formatadora.

Mesma tradicionalidade encontrada na vertente conservadora da Educação Ambiental centrada no indivíduo, com enfoque no ato educativo a partir de um padrão idealizado de relações com a Natureza, contribuindo com o dualismo natureza-cultura que tende à passividade, sem críticas ou resistência à ordem social estabelecida e às suas origens históricas (LOUREIRO, 2004). Esta vertente, segundo Loureiro (2004), apresenta três características principais: i) Educação, entendida enfaticamente em sua dimensão individual, fundamentada em sensibilização, com baixa compreensão das mediações sociais; ii) Educação pouco articulada à coletividade, à problematização e à transformação da realidade que tem como consequência a crença ingênua de que mudanças são obtidas mediante desdobramento de comportamentos individuais; e a iii) Biologização social que ignora a predominância regente exploratória do capitalismo das relações modernas e associa a degradação planetária à humanidade como um todo sem que se situem os grupos sociais, as organizações e as produções empreendidas, resultando em recorrentes de discursos com pouco poder efetivo de mudança.

A multiplicidade de categorias elencadas às práticas da Educação Ambiental: popular, crítica, política, comunitária, conservacionista, socioambiental, entre outras, situadas no campo ético-político, podem ser bastante distintas, de acordo com o posicionamento político-pedagógico e as práticas a elas relacionadas, tornando-se necessário situar 0 ambiente conceitual e político onde a Educação Ambiental pode buscar sua fundamentação, enquanto projeto educativo que pretende transformar a sociedade (CARVALHO, 2004).

A Educação Ambiental de conteúdo emancipatório e transformador é aquela compreendida num movimento ético e material que promove alterações de atividade humana, vinculadas ao fazer educativo, o compromisso com a 
transformação societária e a intransigência na defesa dos valores, atitudes e ações coletivas condizentes com a emancipação (LOUREIRO, 2006). Compartilha as matrizes político-pedagógicas libertadoras de Freire e sustenta o acréscimo de especificidade de compreensão das relações sociedadenatureza para intervenção qualificada sobre os problemas e conflitos ambientais.

Afirma uma ética ambiental balizadora das decisões sociais e reorientadora dos estilos de vida coletivos e individuais, revelando-se como um dos caminhos de transformação que desponta da convergência entre mudança social e ambiental, ao ressignificar o cuidado para com a natureza e para com o outro ser humano como valores ético-políticos (CARVALHO, 2004). Valores encontrados na Teoria Crítica que "pretende denunciar situações e fenômenos sociais a partir da constatação de que uma sociedade sem exploração é a única alternativa para que se estabeleçam os fundamentos da justiça, da liberdade $e$ da democracia" (FARIA, 2018, p. 9).

Fundamentada essencialmente em critérios específicos para análise social, a Teoria Crítica, segundo Faria (2018), não se limita a análises que se destinam a explicar o mundo com base no sujeito, nas unidades de produção ou que se encerram no plano da macrossociedade. Antes, incumbe-se da formulação de mecanismos que desvelem a realidade mediante compreensão das relações sociais, dos sujeitos e de sua inserção nestas relações "para além do que pode ser visto e imediatamente entendido pela sociedade" (p. 9). Constitui-se a partir das análises críticas.

As análises críticas, por vezes, são erroneamente compreendidas como "denuncismos" sem legítimo intuito construtivo e com fins em si mesmos. Compreensões estas, ingênuas e equivocadas haja vista que ao apresentarem as problemáticas fundamentadas criticamente, avanços são alçados em distintas amplitudes, viabilizados pelas organizações coletivas deflagradas (FARIA, 2018). Deste modo, a Educação Ambiental, nesta perspectiva crítica especificamente, não apenas denuncia as mazelas ambientais e sociais as expondo como resultados trágicos das inconsequentes ações humanas em seu mecanismo de produção exacerbadamente desnecessário e subsequente consumo insaciável, como anuncia a coletividade e o exercício da democracia como mecanismos eficazes de enfrentamento efetivo de suas causas.

As similitudes objetivas dos princípios pedagógicos freireanos e dos princípios críticos da Educação Ambiental, são historicamente apresentadas por Carvalho (2004), Guimarães (2004), Loureiro (2006), Pernambuco e Silva (2006), entre outros importantes autores. Layrargues (2004), contextualiza Educação Ambiental como um termo composto por um substantivo e por um adjetivo, que indicam os campos da Educação e do Ambiente. Assim, enquanto o substantivo "Educação" define os fazeres pedagógicos e a prática educativa, - adjetivo "Ambiental" contextualiza esta prática educativa. Ou seja, a adjetivação relaciona-se à motivação da ação pedagógica.

$O$ adjetivo vai então, se referindo a uma classe de características que qualificam essa prática educativa, diante da crise ambiental que o mundo 
vivencia, aclarando inclusive, que a não sustentabilidade (em qualquer âmbito) é uma dessas classes e que, para alcançá-la, necessita-se mais do que uma reforma, necessita-se de transformação. Mais uma vez a aclamada transformação!

Interessante atentar que se desvincula o ambiente à educação, o excluindo da concepção de educação, como se toda a forma de educação fosse independentemente praticável indissociada ao ambiente. Ambiente aqui, entenda-se, não apenas enquanto espaço, lócus, mas em toda a amplitude de relações, espécies, interações, reinvindicações e enfrentamentos que "ambiente" compreende e que também compõem o cerne da educação. Ao simplificar o termo composto unicamente à análise gramatical do mesmo, tira-se da Educação Ambiental a essencialidade de sua natureza investigativa, crítica e transformadora, limitando sua prática ao campo pedagógico, seja formal, informal ou não-formal, resultando em uma educação que poucos se entendem participantes e responsáveis.

Nesta adjetivação, ainda, percebe-se mais que uma forma simplista, ingênua de vislumbrá-la; inferindo-se a partir dela, que a prática educativa pedagógica não precisa comprometer-se amplamente com a prática da Educação Ambiental, uma vez que se compreende separada a ela, à parte, apenas uma área de especificidade dentre as demais existentes. A responsabilidade quanto à sua implementação, deste modo, torna-se subentendida restrita, de modo geral, àqueles ligados a graduações que a contemplam como parte do currículo ou profissionais atuantes no campo; não como responsabilidade de todos. O que é de todos, não é de ninguém, já diria o ditado popular.

Frente ao exposto, evidencia-se assim que, o adjetivo "Ambiente" associado a "Educação", compondo este conceito composto "Educação Ambiental" revela muito além de uma classificação de especificidade pedagógica ou mesmo gramatical. É parte inerente indispensável da educação essencialmente transformadora, acrescida de especificidade quanto aos seus fundamentos balizadores, sua ampla atuação, objetivos e enfrentamentos.

Vale ressaltar que não se anela romantizar a Educação Ambiental, exaltando-a como resposta absoluta para toda e qualquer desigualdade socioambiental nem tampouco minimizar a luta que este termo composto carrega em seu âmago, resultado de anos de militância, nem tampouco aviltar a compreensão de "a verdadeira educação ser ambiental por excelência" (MORALES, 2008, p. 17). Esta afirmação de uso relativamente comum, mostrase como verdade quando condicionada ao entendimento e a não abstração da especificidade inerente à Educação Ambiental.

Freisleben (2013), afirma que Educação Ambiental configura-se como educação que ocorre nos ambientes como objeto de investigação das ciências, constituindo-se num processo eficaz para reflexão epistemológica, compreendendo o sujeito como ser que "se constitui mediado pelas determinações sociais, com capacidade de (re)significar valores e práticas 
sociais, transformando a si e o meio ambiente no qual está inserido" (FREISLEBEN, 2013, p. 101-102). Explicita ainda, quanto à necessidade de compreensão de que a educação se faz mediadora do desenvolvimento cultural e histórico humano e que, portanto,

os estudos sobre a Educação Ambiental devem iniciar, exatamente, pelo entendimento dos saberes que os indivíduos e as comunidades já construíram sobre estes elementos ao longo do tempo e que se tornam visíveis nas suas ações [...] A Educação Ambiental como processo educativo, acontece e é permanente, quando adquirimos base para atuar com conhecimento, com responsabilidade e com atitudes no meio ambiente na perspectiva social-cultural e dialética (FREISLEBEN, 2013, p. 102).

Para tanto, é de primordial importância a construção de uma nova compreensão social de mundo, em um exercício de cidadania, na participação em movimentos coletivos conjuntos de transformação da realidade socioambiental, como esclarece Guimarães (2004).

Bonassina e Kuroshima (2021, p. 166) afirmam que a dimensão ambiental "envolve um conjunto de atores do universo educativo para potencializar o engajamento dos diversos sistemas do conhecimento [...] para que os problemas ambientais sejam amenizados ou solucionados". Em concordância, Jacobi et al. (2009) trazem o conceito "sociedade de risco" como conceito reflexivo quanto a complexa temática das relações entre sociedade, meio ambiente e educação, partindo do pressuposto da sociedade como "produtora de riscos", especialmente nos âmbitos ambientais e tecnológicos de graves consequências. Esta sociedade "produtora de riscos" torna-se cada vez mais reflexiva, mais autocrítica, e o conceito de risco passa a ocupar um papel estratégico para entender as características, os limites e as transformações do projeto histórico da modernidade, evidenciando a reflexão a respeito desta sociedade que permite abordar a complexa temática das relações entre sociedade, meio ambiente e educação.

Por contemplar de maneira integrada os âmbitos supracitados, a Educação Ambiental proporciona ação ampla, produzindo culturas ambientais, desde suas matrizes políticas e pedagógicas, influindo sobre a maneira como os grupos sociais dispõem dos bens ambientais e imaginam suas perspectivas de futuro (CARVALHO, 2004), conduzindo ao apreender quanto ao pertencimento significativo, a responsabilidade e ao seu nível de atuação no equilíbrio ecossistêmico ao qual se está inserido. Outrossim, as "controvérsias que surgem na dinâmica dos recursos naturais-população, desenvolvimento socioeconômico-ambiental, consumo de produção, etc." (CARIDE; MEIRA, 2001, p. 27, tradução da autora), perpassam obrigatoriamente a transformação do formato de desenvolvimento social e econômico, incluindo as bases relacionais 
ecossistêmicas das quais a humanidade é participante direta ou indiretamente, ainda que não se perceba parte delas.

Relações de equilíbrio e interdependência existentes entre os elementos naturais constituintes de um ecossistema e que suscitam consequentes repercussões a todo um sistema, em caso de interferência ou quebra de equilíbrio ecossistêmico (BIFANI, 1999, p. 262, apud. CARIDE; MEIRA, 2001). Sejam as alterações sofridas de caráter quantitativo ou qualitativo, ainda assim, as consequências repercutem sobre todos os elementos formadores do ecossistema em questão, afinal de contas, o "intercâmbio mutuamente constituinte entre partes e todo não é apenas orgânico, mas socialmente ativo" (LOUREIRO, 2006, p. 143).

Para Guimarães (2004), a visão social de mundo tem pilares na crise ambiental da atualidade e sustenta a "relação desintegrada entre sociedade $e$ natureza, baseada na dominação e espoliação da primeira sobre a segunda" (2004, p. 26), em conformidade com o exposto por Caride e Meira (2001), que expõem as crises civilizatória e ambiental como uma única crise, a crise social.

Para Sorrentino et al. (2005, p. 285)

A Educação Ambiental surge como uma das possíveis estratégias para o enfrentamento da crise civilizatória de dupla ordem, cultural e social. Sua perspectiva crítica e emancipatória visa à deflagração de processos nos quais a busca individual e coletiva por mudanças culturais e sociais estão dialeticamente indissociadas.

Neste contexto, as ações de caráter individual mostram-se pouco efetivas, ainda que necessárias, frente à prática que se revela como macrotendência social: a polarização posicional entre qualidade de vida e qualidade ambiental. Se a divergência entre sociedade e natureza decorre de benefício único de "uma das partes", logo, a desembaraçada percepção de que considerável "parte das relações que os cidadãos das sociedades urbanas mantêm com a Natureza são geralmente conduzidas, cada vez mais dependentes de atos de consumo" (CARIDE; MEIRA, 2001, p. 60, tradução da autora), emerge.

Não há como desenvolver as condições de debate e autoexame explanadas por Freire em sua fala sobre a democracia, nem tampouco a implementação dos conceitos e vivências basilares da Educação Ambiental, sem que haja postura dialógica entre sociedade, meio ambiente e educação, além de ressignificação quanto as relações de interdependência delas.

Educar para emancipar é reconhecer os sujeitos sociais e trabalhar com estes em suas especificidades. A práxis educativa 
transformadora é, portanto, aquela que fornece ao processo educativo as condições para a ação modificadora e simultânea dos indivíduos e dos grupos sociais; que trabalha a partir da realidade cotidiana visando à superação das relações de dominação e de exclusão que caracterizam e definem a sociedade capitalista globalizada (LOUREIRO, 2006, p. 149).

À luz disto, importa destacar que "à nossa cultura fixada na palavra corresponde a nossa inexperiência do diálogo, da investigação, da pesquisa, que, por sua vez, estão intimamente ligados à criticidade, nota fundamental da mentalidade democrática" (FREIRE, 1999, p. 207). Portanto, indubitavelmente, a essência da democracia, dos conceitos político-pedagógicos freireanos e dos preceitos de Educação Ambiental nesta perspectiva crítica e emancipatória, fazse única, ou seja, os três elementos em questão, assim, nunca estiveram desconexos. Ao contrário, são vertentes de uma mesma luta que os fazem, por essência, complementares.

\section{Considerações finais}

A instabilidade no cenário político e econômico, resultante das repetidas mudanças desde o período pós-independência, afetou consideravelmente as comunidades insulares de Guiné-Bissau. O Arquipélago dos Bijagós tem sofrido pela pressão da cobiça humana exercida sobre ele há anos, em especial no que se refere à exploração excessiva dos recursos naturais e turísticos, potencializado por legislações frágeis e de limitada competência protetiva, ameaçando seu potencial econômico, equilíbrio ecológico e contribuindo para o aumento de sua fragilidade.

A transformação socioambiental, segundo Guimarães (2004), perpassa a compreensão complexa do real a fim de que se instrumentalizem os atores sociais para intervenção desta realidade. Diante desta reflexão, inevitavelmente, retoma-se o questionamento inicial: De que maneira pode-se promover transformação socioambiental em Bubaque (Guiné-Bissau) através da Educação Ambiental associada às práticas político pedagógicas freireanas, tendo como pressupostos o sentimento de responsabilidade e pertencimento, preservação dos recursos naturais e autonomia socioeconômica da comunidade? Os dados levantados, apresentados e discutidos explicitam o quão distante estamos de responder a esta pergunta, entretanto, oportuniza o aprofundamento das reflexões por ela provocadas.

A articulação de transformação de uma sociedade em todos os seus âmbitos, perpassa as relações sociais, o exercício genuíno da democracia e o entendimento coletivo de pertencimento, amor e responsabilidade. Quando a democracia é suprimida, menor a expressão de criticidade e tanto mais ingenuamente os problemas são tratados, sendo discutidos superficialmente (FREIRE, 1999), o que torna compreensível a não definição democrática de um 
país que teve como base de seus enfrentamentos por independência, a democracia.

Tornam-se igualmente compreensíveis, as razões pelas quais as ineficazes ações por parte do Estado, tanto em salvaguardar seu patrimônio natural da exploração que o ameaça, quanto em promover leis amparadas pela essencial fiscalização que as faça cumprir, mostram-se frágeis e insuficientes. Evidencia-se ainda, a educação como alicerce fundamental de democratização para formação do sujeito ativo transformador a partir do enfrentamento da crise civilizatória e a Educação Ambiental como ferramenta articuladora emancipatória aplicada à deflagração de processos nos quais a busca por mudanças culturais, sociais e ambientais estão, dialeticamente, indissociadas.

Se a ação emancipatória depende de contínua crítica reflexiva e autocrítica para o rompimento do padrão vigente de sociedade e de civilização, expõem-se o engajamento necessário para o disparo de um processo societário que movimente o "lugar" ocupado por cada sujeito, estabelecendo experiências formativas, escolares ou não, onde a reflexão problematizadora da totalidade seja apoiada na ação política, propiciando então, a construção da dinâmica necessária (LOUREIRO, 2006). Dinâmica esta, fundamentada e construída mediante enfrentamentos, conquistas e ações compromissadas com a transformação social e com a defesa dos valores condizentes com a emancipação, com a coletividade e com o aprofundamento dialógico, haja vista que sem ampliação dialógica, a ação emancipatória se faz incompleta pois, conforme elucida Freire, "a distância social existente e característica das relações humanas no grande domínio, não permite a dialogação [...]. A dialogação implica na responsabilidade social e política do homem" (1999, p. 70).

Espera-se portanto, que as denúncias relatadas no presente artigo e as reflexões por ele provocadas, desvelem-se em futuras pesquisas que promovam abertura à dialogação, à democracia, à criticidade, desenvolvidas através da implementação de uma educação libertadora, que promovam novamente a transitividade à sociedade guineense e que possibilitem tanto a Bubaque quanto às demais ilhas habitadas do Arquipélago das Bijagós (Guiné-Bissau), desenvolver e vivenciar autonomia, sentimento de pertencimento e de responsabilidade socioambiental que resultem no país reconstruído e fortalecido pela força e poder de seu povo.

\section{Referências}

BALLESTRIN, L. América Latina e o Giro Decolonial. Brasília: Revista Brasileira de Ciência Política, n. 11, p. 89-117, 2013.

BONASSINA, A.L.B.; KUROSHIMA, K.N. Impactos do Ensino, Pesquisa e Extensão Universitária: instrumento de transformação socioambiental. Revista Brasileira de Educação Ambiental, v.16, n. 1, p.163-180, 2021. 
BRUNDTLAND, G.H. Nosso Futuro Comum: comissão mundial sobre meio ambiente e desenvolvimento. Rio de Janeiro: Instituto de Documentação Editora da Fundação Getúlio Vargas, 1988.

CARIDE, J.A.; MEIRA, P.A. Educación Ambiental y Desarrollo Humano. $1^{\text {a }}$ ed., Barcelona: Ed. Ariel Educación, 2001.

CARVALHO, I.C.M. Educação Ambiental Crítica: nomes e endereçamentos da educação. In: LAYRARGUES, P.P. (Org.) Identidades da Educação Ambiental Brasileira. Brasília: Ministério do Meio Ambiente, 2004. p. 13-24.

CHAUÍ, M. Cultura e Democracia. 2ª ed. Salvador: Secretaria de Cultura, 2012. CRUZ, G.A. Direito do Ambiente e Teoria da Normação na Guiné-Bissau: de uma teoria do Direito do Ambiente guineense ao seu contributo para a teoria e prática da normação na Guiné-Bissau. UICN Serviço de Publicação. Alemanha: Estudo de Política e Ambiente da UICN, N.42, 2000.

FARIA, J.H. Por Uma Teoria Crítica da Sustentabilidade. ResearchGate, $2018 . \quad$ Disponível em: $<$ https://www.researchgate.net/publication/325999231 POR UMA TEORIA C RITICA DA SUSTENTABILIDADE>. Acesso em: 15/08/2021.

FREIRE, P. Cartas à Guiné-Bissau: registros de uma experiência em processo. $2^{\underline{a}}$ ed., Rio de Janeiro, Paz e Terra, 1978.

FREIRE, P. Educação Como Prática da Liberdade. 23르 ed. Rio de Janeiro: Paz e Terra, 1999.

FREISLEBEN, P.A. A Educação Ambiental na Perspectiva Dialética Materialista. Mato Grosso: Revista Eletrônica Geoaraguaia, vol. 3, n.2, p 100 112, 2013.

GUIMARÃES, M. Educação Ambiental Crítica. In: LAYRARGUES, P.P. (Org.) Identidades da Educação Ambiental Brasileira. Brasília: Ministério do Meio Ambiente, 2004. p. 25-34.

JACOBI, P.R.; TRISTÃO, M.; FRANCO, M.I.G.C. A Função Social da Educação Ambiental nas Práticas Colaborativas: participação e engajamento. Campinas: Cad. Cedes, vol. 29, n. 77, p. 63-79, 2009.

JACOBI, P.R. Educação Ambiental: o desafio da construção de um pensamento crítico, complexo e reflexivo. São Paulo: Educação e Pesquisa, v. 31, n. 2, p. 233-250, 2005.

LAYRARGUES, P.P. (Re)Conhecendo a Educação Ambiental Brasileira. In: LAYRARGUES, P.P. Identidades da Educação Ambiental Brasileira. Brasília: Ministério do Meio Ambiente, 2004. p. 7-9.

LOUREIRO, C.F.B. Complexidade e Dialética: contribuições à práxis política e emancipatória em Educação Ambiental. Cad. Cedes, Campinas, vol. 27, n. 94, 2006. 
LOUREIRO, C.F.B. Educação Ambiental Transformadora. In: LAYRARGUES, P.P. (Org.) Identidades da Educação Ambiental Brasileira. Brasília: Ministério do Meio Ambiente, 2004. p. 65-84.

MADEIRA, J.P. Bijagos Archipelago: impacts and challenges for environmental sustainability, Grajaú/MA, InterEspaço, v.2, n.5 p. 291-305, 2016.

MORALES, A.G.M. Processo de Institucionalização da Educação Ambiental. Curitiba: Cadernos Temáticos da Diversidade 1. Paraná: Secretaria de Estado da Educação - SEED, 2008.

OLIVEIRA, A.L.A.; CARVALHO, F.M.; OLIVEIRA, F.F.; OLIVEIRA Jr, A.F.O; MOREIRA, S.M. Inovação em Educação Ambiental: um estudo de caso sobre a trilha dos sentidos do Parque Estadual Mata do Limoeiro. Revista Brasileira de Educação Ambiental, v.16, n. 3, p.429-438, 2021.

PANZO, T.I Educação Ambiental nos países lusófonos e a sua contribuição para um desenvolvimento sustentável. In: Confluências de culturas no mundo lusófono -XXVII Encontro Associação das Universidades de Língua Portuguesa CAMPINAS, BRASIL, 2017.

PERNAMBUCO, M.M.; SILVA, A.F.G. Paulo Freire: a educação e a transformação do mundo. Ed. Eletrônica. Brasília: Ministério da Educação, 2006. Disponível em: http://portal.mec.gov.br/dmdocuments/publicacao4.pdf Acesso em: 10/11/2020.

POLET, F.; BARROS, M.; RAMOS, E. Dinâmicas e Impactos da Expansão do Turismo no Arquipélago dos Bijagós Guiné-Bissau: IMVF e Tiniguena, 2011. Disponível https://issuu.com/imvf/docs/dinamicas e impactos da expansao do turismo Acesso em: 15/07/2021.

SEN, A.K. Desenvolvimento Como Liberdade. São Paulo: Companhia das Letras, 2000.

SORRENTINO, M.; TRAJBER, R.; MENDONÇA, P.; FERRARO Junior, L.A. Educação Ambiental Como Política Pública. Educação e Pesquisa, v.31, n.2, pp.285-299.

SUCUMA, A. Breve Histórico Sobre a Construção do Estado da Guiné-Bissau. Pernambuco: Cadernos de História da UFPE - Revista do Departamento De História da Universidade Federal de Pernambuco, 2017. Disponível em: https://periodicos.ufpe.br/revistas/cadernosdehistoriaufpe/article/view/110099 ISSN: 2594-3766. Acesso em: 10/11/2020.

TEIXEIRA, C. Educação e Desenvolvimento Sustentável na Agenda 21 Brasileira. Goiás: Revista Inter-Ação, n. 33, p. 31-48, 2008. 